\title{
On the possibility of inhibition of zinc corrosion by phosphonates and formulations on their basis ${ }^{1}$
}

\author{
G.V. Redkina,* A.S. Sergienko and Yu.I. Kuznetsov \\ A.N. Frumkin Institute of Physical Chemistry and Electrochemistry, Russian Academy of \\ Sciences, Leninsky pr. 31, 119071 Moscow, Russian Federation \\ *E-mail: GVRedkina@mail.ru
}

\begin{abstract}
Corrosion and electrochemical methods are used to study the effect of 1-hydroxyethane-1,1diphosphonic acid zinc complex (HEDPZn) or its formulation with sodium metanitrobenzoate $(m-\mathrm{SNB})$ on the corrosion-electrochemical behavior of zinc in a borate buffer solution with $\mathrm{pH} 7.4$ containing $1 \mathrm{mM} \mathrm{NaCl}$ and in a humid atmosphere with daily moisture condensation. It was shown that HEDPZn has an inhibiting effect on the corrosionelectrochemical behavior of zinc both in a chloride-containing borate buffer solution and under harsh conditions of $100 \%$ relative humidity. The inhibiting ability of HEDPZn depends on its concentration $\left(C_{\mathrm{CI}}\right)$, the time of exposure $\left(\tau_{\text {pas }}\right)$ of the metal in the solution with the corrosion inhibitor, and the solution temperature $\left(t_{\mathrm{pas}}\right)$. Addition of the oxidizer, $m$-SNB, enhances the inhibiting properties of HEDPZn in zinc passivation. Increasing the temperature of the passivating solution, treatment time and inhibitor concentration facilitates the formation of protective layers on zinc samples by the mixture of HEDPZn with $m$-SNB and enhances their resistance in a humid atmosphere. Layer-by-layer passivation of zinc by the equimolar inhibitor formulation consisting of HEDPZn and $m$-SNB with $C_{\mathrm{CI}}=32.0 \mathrm{mM}$ at $t_{\mathrm{pas}}=40^{\circ} \mathrm{C}$ and $\tau_{\mathrm{pas}}=60 \mathrm{~min}$ with subsequent treatment in a solution of sodium oleate with $C_{\mathrm{CI}}=16.0 \mathrm{mM}$ at $t_{\mathrm{pas}}=40^{\circ} \mathrm{C}$ and $\tau_{\mathrm{pas}}=20 \mathrm{~min}$ allows one to increase 8-fold its corrosion resistance under harsh conditions of $100 \%$ relative humidity with periodic condensation of moisture on the samples.
\end{abstract}

Keywords: zinc, passivation, adsorption, corrosion inhibitor, phosphonates, zinc 1-hydroxyethane-1,1-diphosphonate (HEDPZn).

Received: July 6, 2019. Published: September 2, 2019

doi: $\underline{10.17675 / 2305-6894-2019-8-3-16}$

\section{Introduction}

The use of phosphonic acids and their complexes as corrosion inhibitors (CI) was proposed as far back as in the beginning of the 1970s [1], and since then a lot of works have been

\footnotetext{
${ }^{1}$ The study was carried out as part of the Program of Fundamental Scientific Research of the State Academies of Sciences for 2013-2020, subject: "Development of the fundamental scientific basis of the protective action of metal corrosion inhibitors in gas and condensed media, nanocomposites, paint and conversion coatings" (state registration number AAAA-A18-118121090043-0).
} 
devoted to their study. The interest of researchers in phosphonate CIs is due to their high reactivity, relatively low toxicity and industrial availability. 1-Hydroxyethane-1,1diphosphonic acid (HEDP) is one of the best-known representatives of this class of CI widely used in practice. It has a number of unique properties due to the specific stereochemistry and the presence of two phosphonic groups $\left(-\mathrm{PO}_{3} \mathrm{H}_{2}\right)$ in the molecule. Thus, HEDP forms complex compounds, complexonates, with cations of a lot of metals, including zinc, with high stability constants in a wide $\mathrm{pH}$ range. In addition, the unrealized denticity of HEDP determines its ability to form stable polynuclear complexes [2]. Even though the tendency of phosphonic acids to form strong complex compounds with $\mathrm{Zn}^{2+}$ cations has long been known, their effect on the corrosion-electrochemical behavior of zinc and its alloys remains relatively little studied [3]. Thus, Aramaki investigated the protective properties of sodium 1-hydroxyethane-1,1-diphosphonate (HEDPNa) with respect to zinc in aerated $0.5 \mathrm{M} \mathrm{NaCl}$ solution [4]. According to electrochemical measurements, HEDPNa stimulated the anodic dissolution of zinc at concentrations of 3 and $10 \mathrm{mM}$, shifting its corrosion potential to negative values. The author logically associated this with the formation of soluble complexes of HEDP with $\mathrm{Zn}^{2+}$.

The mechanism of phosphonic acids action, first proposed in [5] for steel, is based on the possibility of phosphonic acid interaction with the metal surface in the near-electrode layer, leading to the formation of soluble $\mathrm{Me}-\mathrm{L}$ complexes (where $\mathrm{L}$ is the ligand) in accordance with the reaction:

$$
n \mathrm{Me}^{a+}+m \mathrm{~L}^{b-}=\mathrm{Me}_{n} \mathrm{~L}_{m}^{(m b-n a)-}
$$

It is known that the hardly soluble complexonates are formed with a deficiency of ligand molecules or an excess of complexing cations $(n>m)$ [2]. Compensation of the negative charge of the ligand during complexation with the metal cation increases the hydrophobicity of the compound, increasing its surface activity. If the forming complex is hardly soluble, then, accumulating at the interface, it must shield the metal surface from further dissolution and thereby inhibit corrosion. This mechanism of inhibition probably can be expected for the zinc complex of HEDP at zinc dissolution, when a high ratio of the activity of the metal cation and ligand $\left(n=\left[\mathrm{Me}^{a+}\right] /\left[\mathrm{L}^{b-}\right]\right)$ can lead to the formation of the hardly soluble polynuclear complexes [2].

It is known that one of the possible ways to improve the protective properties of phosphonates and to decrease their minimum protective concentration is the use of their formulations with an oxidizer [6-9]. According to the mechanism of action of phosphonates, alkalization of the near-electrode layer can lead to deprotonation of the inhibiting complex, which enables the formation of binuclear complexes with high stability constants [2]. Oxidizers of another type, which can either be reduced at a higher rate than oxygen or generate more $\mathrm{OH}^{-}$ions per unit transferred charge upon reduction, can compete with dissolved oxygen in this process. Sodium meta-nitrobenzoate $(m-S N B)$ belongs to the former type of oxidizers. It is reduced by the reaction [10]: 


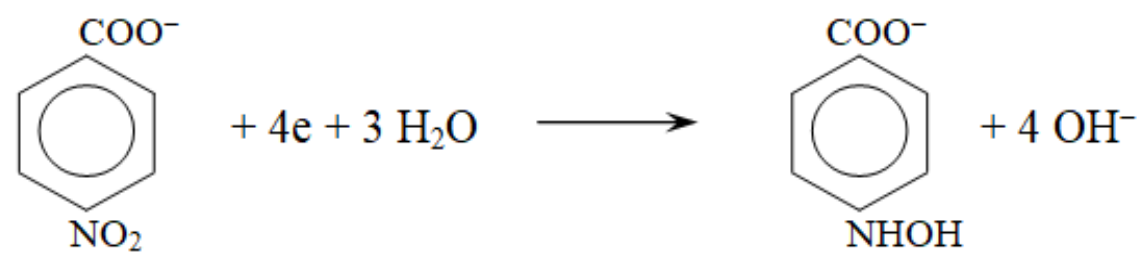

Sodium nitrite, a well known CI, belongs to the second type of oxidizers. Its reduction can be represented by the reaction:

$$
\mathrm{NO}_{2}^{-}+6 e+6 \mathrm{H}_{2} \mathrm{O}=\mathrm{NH}_{4}^{+}+8 \mathrm{OH}^{-}
$$

It is preferable to use $m$-SNB as a component of the inhibiting formulation for zinc, since it is a CI of oxidative type for ferrous and non-ferrous metals like some other organic nitro compounds, reduction of which does not produce oxides and/or hydroxides [6]. In this regard, the sodium nitrite can be dangerous, because it can stimulate zinc pitting corrosion [11].

It is known that phosphonates can be used for modification of metal surfaces, for example, low carbon steel in order to enhance its passivation by aqueous solutions of other inhibitors (carboxylates, azoles, and their mixtures) [12-14]. In essence, this method represents a two-step treatment of the metal surface. At first, the latter is modified by adsorption of certain compounds or by treatment in solutions of inhibitors giving rise to more complex changes of the metal surface, for instance, surface reactions and deposition of complex compounds. This can strengthen the subsequent adsorption of another inhibitor, thus facilitating the passivation.

In view of this, in the present work we investigated the inhibition of zinc corrosion by zinc 1-hydroxyethane-1,1-diphosphonate and its formulations with $m$-SNB, as well as the possibility of using this formulation in layer-by-layer passivation of zinc together with a carboxylate-type CI in order to enhance the corrosion resistance of zinc in a humid atmosphere.

\section{Experimental}

In this work, we used zinc (GOST 3640-94) with a $\mathrm{Zn}$ content of $99.975 \%$ and up to $0.025 \%$ of $\mathrm{Fe}, \mathrm{Al}, \mathrm{Cu}, \mathrm{Sn}, \mathrm{Pb}, \mathrm{Cd}$, and As impurities. The background electrolyte was a borate buffer solution with $\mathrm{pH} 7.4$ containing $1.0 \mathrm{mM} \mathrm{NaCl}$. The CIs used included the zinc complex of 1-hydroxyethane-1,1-diphosphonic acid $\left(\mathrm{CH}_{3} \mathrm{C}(\mathrm{OH})\left(\mathrm{PO}_{3} \mathrm{H}_{2}\right)_{2}, \mathrm{HEDPZn}\right)$, sodium oleate $\left(\mathrm{NaC}_{17} \mathrm{H}_{33} \mathrm{COO}\right.$, SOL), and $m$-SNB $\left(\mathrm{C}_{6} \mathrm{H}_{4} \mathrm{NO}_{2} \mathrm{COONa}\right)$. In the preparation of the HEDPZn complex, the cation:ligand ratio in the complex was selected from the stoichiometry of formation of mononuclear complexes (1:1). The $\mathrm{Zn}^{2+}$ cation was added in the form of zinc oxide. The $\mathrm{pH}$ of the concentrated phosphonate aqueous solution was maintained in the range of $7.7 \pm 0.2$ by $\mathrm{NaOH}$ solution. All solutions were made of reagents of "chemically pure" or "pure for analysis" grades and distilled water. 
Electrochemical studies were carried out using cylindrical zinc samples with a work surface of $S=0.72 \mathrm{~cm}^{2}$. Potentiodynamic polarization curves of zinc were recorded in a glass two-compartment electrochemical cell using an IPC-Pro MF potentiostat (Russia). A saturated silver chloride reference electrode and a platinum counter electrode were used. Prior to each experiment, the working electrode was cleaned using abrasive paper with different grain sizes until a mirror finish was obtained, and then degreased by acetone. To remove the oxide film formed in air before measuring the polarization curve, the electrode was activated for $15 \mathrm{~min}$ at potential $E=-1.1 \mathrm{~V}$ and then kept for $15 \mathrm{~min}$ until free corrosion potential $\left(E_{\text {corr }}\right)$ was established. A solution of the CI was added after a new $E_{\text {corr }}$ value was established and its value was maintained using a potentiostat. Polarization was switched off, and the polarization curves were measured after $15 \mathrm{~min}$ of exposure and establishing the new $E_{\text {corr }}$ value with the potential scan rate $V=0.2 \mathrm{mV} / \mathrm{s}$.

Electrochemical evaluation of protective properties of the films previously formed on zinc in the CI solution was carried out in the following way: the electrode was immersed in an aqueous solution of $\mathrm{CI}$ with continuous stirring at various $\mathrm{CI}$ concentrations $\left(C_{\mathrm{CI}}\right)$, exposure times $\left(\tau_{\text {pas }}\right)(20,60$ and $120 \mathrm{~min})$ and solution temperatures $\left(t_{\text {pas }}\right)\left(20\right.$ and $\left.40^{\circ} \mathrm{C}\right)$. The protective layers of $\mathrm{CI}$ on zinc were formed on the electrode surface naturally oxidized in air (for $30 \mathrm{~min}$ ). After the passivation, the samples were air-dried for $30 \mathrm{~min}$. The electrode treated in this way was screwed onto the holder and placed into the electrochemical cell. Anodic polarization was started immediately once the electrode was immersed into the background electrolyte. The efficiency of zinc protection was assessed by the difference of potentials of local depassivation $\Delta E=E_{\mathrm{pt}}^{\mathrm{in}}-E_{\mathrm{pt}}^{\mathrm{bg}}$ determined from polarization curves measured in borate buffer solution containing $\mathrm{NaCl}$ either in the absence $\left(E_{\mathrm{pt}}^{\mathrm{bg}}\right)$ or in the presence of the inhibitor $\left(E_{\mathrm{pt}}^{\mathrm{in}}\right)$. All experiments were carried out at room temperature of the solution and natural aeration. All electrode potentials were recalculated to the normal hydrogen scale.

The protective properties of passivating layers on the metal were studied under harsh conditions of $100 \%$ relative humidity with periodic condensation of moisture on the samples. Zinc samples were prepared in the same way as it was done for the polarization measurements. Then the passivated samples were hanged in a glass cell with a volume of $800 \mathrm{ml}$, with $50 \mathrm{ml}$ of distilled water at $t=50^{\circ} \mathrm{C}$ poured on the bottom. The cells were closed by lids; as water cooled down, active condensation of its vapors on the samples occurred. Water was changed every 24 hours after visual control of the samples in order to determine the time when the first corrosion damage appeared $\left(\tau_{\mathrm{cor}}\right)$.

\section{Results and discussion}

According to electrochemical studies, the free corrosion potential of zinc in a borate buffer solution containing $1 \mathrm{mM} \mathrm{NaCl}$ is $E_{\text {cor }}=-0.77 \mathrm{~V}$, which is in the active dissolution region (Figure 1). During anodic polarization, the curve contains a peak at the passivation potential $E_{\mathrm{P}}=-0.63 \mathrm{~V}$ due to the initial stage of $\mathrm{Zn}(\mathrm{OH})_{2}$ formation [15]. Addition of 
$0.1 \mathrm{mM}$ HEDPZn to the solution leads to a slight decrease in the rate of the anodic process on zinc. Increasing the $C_{\mathrm{CI}}$ to 0.5 and $1.0 \mathrm{mM}$ accelerates zinc dissolution while $E_{\text {corr }}$ is shifted to $0.9 \mathrm{~V}$ in the negative direction and leads to the appearance of another maximum on the polarization curve. Usually the peak of the anodic current at $E=-0.82 \mathrm{~V}$ is associated with the dissolution of zinc in the form of $\mathrm{Zn}^{2+}$. Further increase in the concentration of HEDPZn in the solution to $5 \mathrm{mM}$ is accompanied by a significant stimulation of anodic dissolution of zinc. Possibly it is due to the complex formation between the HEDP ligand and the ions of dissolving zinc, which leads to the formation of soluble zinc complexes in the presence of an excess of the ligand. This phenomenon was described earlier on iron $[5,16]$.

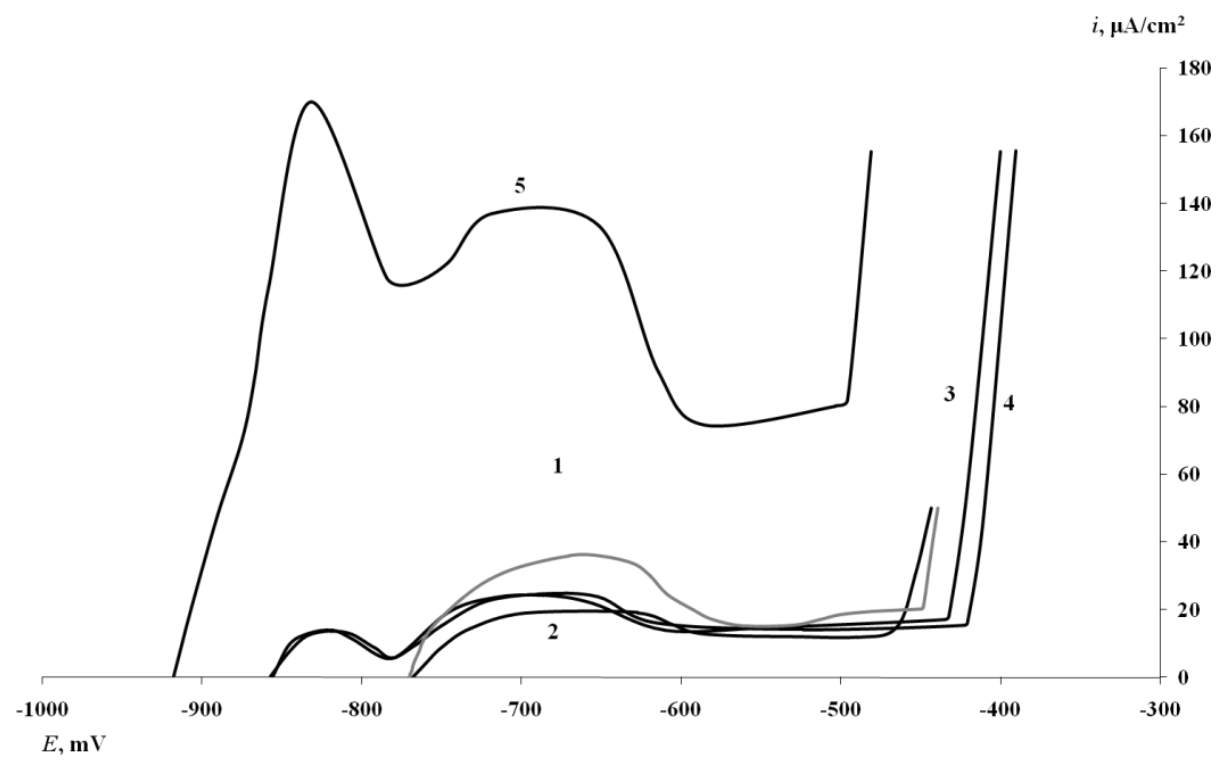

Figure 1. Anodic polarization curves of zinc in borate buffer ( $\mathrm{pH} 7.4)$ containing $1 \mathrm{mM} \mathrm{NaCl}$, without (1) and with HEDPZn (in $\mathrm{mM}$ ): $2-0,5 ; 3-1 ; 4-5$.

The results of electrochemical studies of zinc in chloride-containing buffer solution in the presence of $1.0 \mathrm{mM}$ HEDPZn at various exposure times to establish the free corrosion potential $\left(\tau_{E \mathrm{cor}}\right)$ are shown in Figure 2. It should be noted that even without addition of the CI to the solution, with increasing the $\tau_{E c o r}$, inhibition of the anodic process on zinc is observed, which is accompanied by a decrease in the passivation current density $\left(i_{\text {pas }}\right)$ and a shift of $E_{\mathrm{pt}}$ in the positive direction. It is possibly due to a growth of the thickness of the hydroxide layer on the metal surface. In the presence of $1 \mathrm{mM} \mathrm{HEDPZn}$, an increase in $\tau_{E c o r}$ leads to an increase in its inhibiting properties: $E_{\text {cor }}$ and $E_{\mathrm{pt}}$ increase by $0.08 \mathrm{~V}$ and $0.04 \mathrm{~V}$, respectively. This indicates that more perfect protective phosphonate films resistant to the corrosive effects of chloride ions are formed on zinc.

Additional information on the protective properties of films formed in the presence of HEDPZn can be obtained from the anodic polarization curves of zinc samples prepassivated in phosphonate solutions. Potentiodynamic studies have shown that the preliminary treatment of zinc in an aqueous HEDPZn solution leads to the formation of 
layers with better protective properties than the air-formed oxide layer on its surface. The properties of these surface layers strongly depend on the conditions of their formation $\left(t_{\mathrm{pas}}\right.$, $\left.\tau_{\mathrm{pas}}, C_{\mathrm{CI}}\right)$. Anodic polarization curves of zinc treated in $1 \mathrm{mM}$ HEDPZn solution at $t_{\mathrm{pas}}=20$ and $40^{\circ} \mathrm{C}$ for $60 \mathrm{~min}$ indicate an increase in the protective properties of phosphonate films with increasing $t_{\text {pas }}$ (Figure 3). Indirectly, this may confirm the chemisorption of zinc phosphonate due to the formation of complex compounds between the phosphonate ligand and the dissolved zinc ions, since an increase in temperature usually has a negative effect on physical adsorption, whereas the rate of chemical interactions may increase.

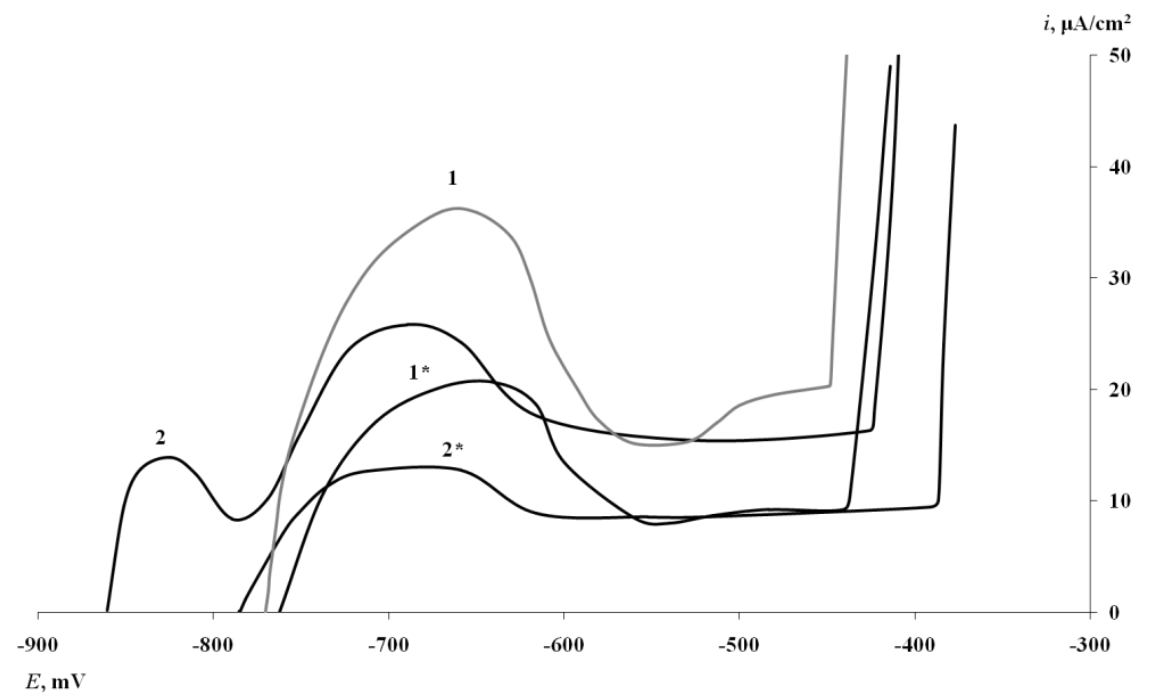

Figure 2. Anodic polarization curves of zinc in borate buffer ( $\mathrm{pH} 7.4)$ containing $1 \mathrm{mM} \mathrm{NaCl}$, without $\left(1,1^{*}\right)$ and with $1 \mathrm{mM} \operatorname{HEDPZn}\left(2,2^{*}\right)$, obtained after $15(1,2)$ and $60 \mathrm{~min}\left(1^{*}, 2^{*}\right)$ of exposure before the establishing of $E_{\text {cor }}$.

Increasing the duration of treatment in a HEDPZn solution at 20 and $40^{\circ} \mathrm{C}$ increases the resistance of the protective phosphonate layers to the corrosive action of chloride ions (Figure $3 \mathrm{a}$ and $\mathrm{b}$ ). Despite the fact that zinc passivation is not observed, an increase in $\tau_{\mathrm{pas}}$ from 20 min to 60 or 120 min leads to even greater inhibition of the anodic process on zinc ( $i_{\mathrm{p}}$ is reduced 1.8-3.5 fold) and an increase in $E_{\mathrm{pt}}$. In addition, the current density in the passive state decreases more than 10-fold, which supports the formation of more perfect protective films in the presence of HEDPZn.

The results of polarization measurements of zinc samples pre-passivated in HEDPZn solutions showed an increase in the protective properties of the films that are formed with a growth in $C_{\mathrm{CI}}$ (Figure 4). The greatest inhibition of the anodic process is observed on zinc pretreated at $t_{\mathrm{pas}}=40^{\circ} \mathrm{C}$ and $\tau_{\mathrm{pas}}=20 \mathrm{~min}$ in an aqueous solution of HEDPZn with $C_{\mathrm{CI}}=16 \mathrm{mM}$, while the value of $i_{\mathrm{p}}$ is reduced 3-fold and $\Delta E=0.036 \mathrm{~V}$. 

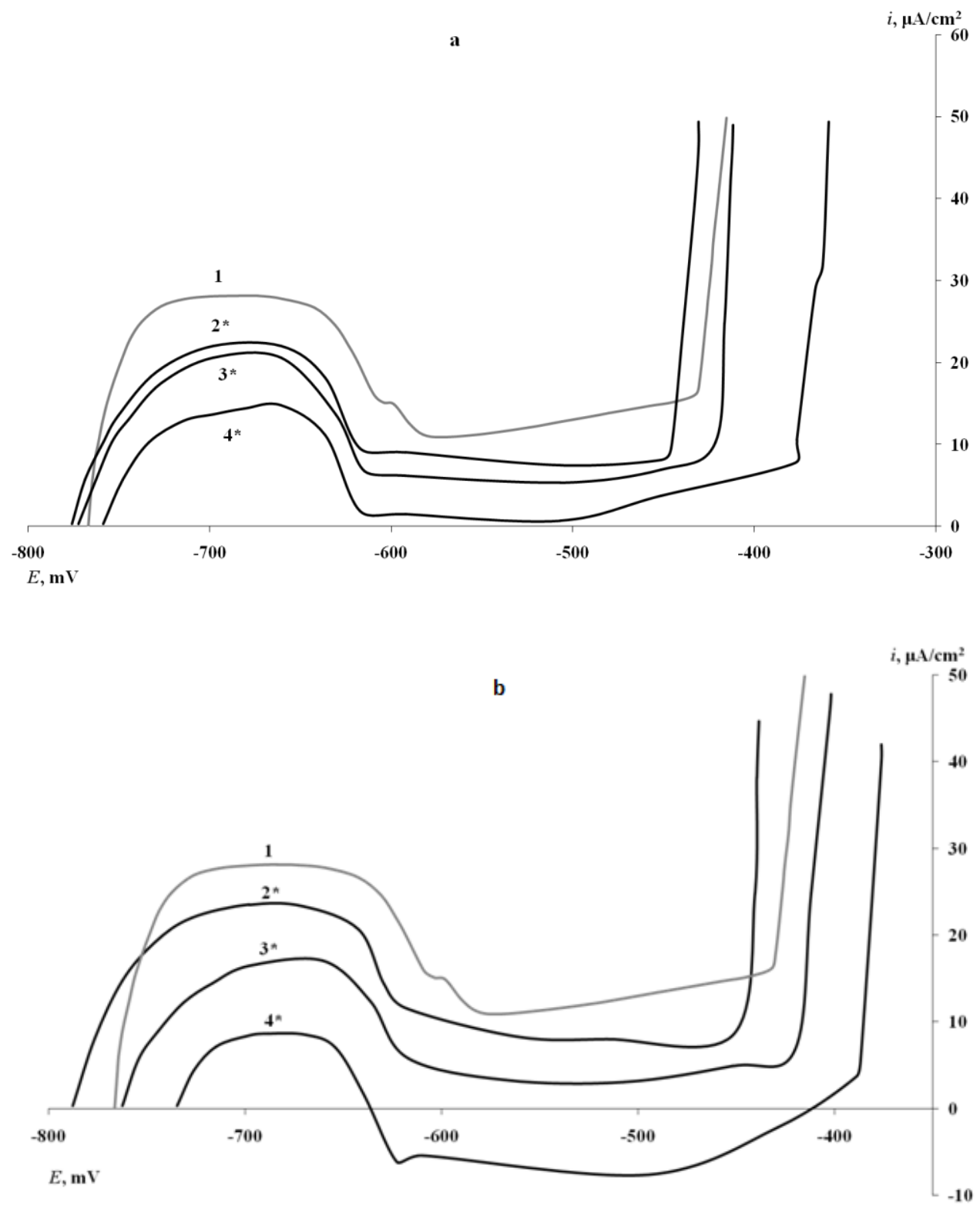

Figure 3. Anodic polarization curves of zinc in borate buffer ( $\mathrm{pH} 7.4)$ containing $1 \mathrm{mM} \mathrm{NaCl}$, without treatment (1) and with pretreatment in solution HEDPZn $(1 \mathrm{mM})$ at 20 (a) and $40^{\circ} \mathrm{C}$ (b) for $20(2,2 *), 60\left(3,3^{*}\right)$ and $120\left(4,4^{*}\right) \mathrm{min}$.

Corrosion tests of zinc samples under harsh conditions of $100 \%$ relative humidity showed that they tarnish and darken with time. After $12 \pm 1 \mathrm{~h}$, there are sections with white corrosion products (so-called "white rust"), the area of which increases over time (Table 1). Though pretreatment of zinc in a solution with a small HEDPZn amount $(1.0 \mathrm{mM})$ increased the resistance in the humid atmosphere by almost half, $\tau_{\text {cor }}=22 \pm 2 \mathrm{~h}$, it did not provide a durable protection of the samples. Moreover, at such a small $C_{\mathrm{CI}}$, neither an increase in $t_{\text {pas }}$ to $40^{\circ} \mathrm{C}$ nor an increase in $\tau_{\text {pas }}$ from 60 to 120 min affected the protective properties of the layers formed on zinc surface in the presence of phosphonate. 
Table 1. Results of corrosion tests of zinc samples, pre-passivated in aqueous solutions of HEDPZn.

\begin{tabular}{|c|c|c|c|c|}
\hline № & $\begin{array}{l}\text { The composition of the } \\
\text { passivating solution }(\mathrm{mM})\end{array}$ & $t_{\mathrm{pas}},{ }^{\circ} \mathrm{C}$ & $\tau_{\text {pas }}$, min & $\tau_{\text {cor }}, h$ \\
\hline 1 & without treatment & - & - & 12.5 \\
\hline \multirow{5}{*}{2} & \multirow{5}{*}{1 HEDPZn } & \multirow{2}{*}{20} & 60 & 19.5 \\
\hline & & & 120 & 20.0 \\
\hline & & \multirow{3}{*}{40} & 60 & 22.0 \\
\hline & & & 120 & 19.5 \\
\hline & & & 150 & 17.5 \\
\hline 3 & 16 HEDPZn & 40 & 60 & 19.0 \\
\hline 4 & 32 HEDPZn & 40 & 60 & 24.0 \\
\hline
\end{tabular}

From the aggregate data of electrochemical and corrosion tests, it can be concluded that HEDPZn has a poor inhibiting effect on the corrosion-electrochemical behavior of zinc both in chloride-containing borate buffer solution and in a humid atmosphere. The inhibitive ability of HEDPZn depends on its concentration and on the exposure time of the metal in a solution with the CI. Increasing the temperature of the passivating solution, the exposure time and $C_{\mathrm{CI}}$ facilitates the formation of protective layers of HEDPZn and increases their stability in a chloride-containing neutral solution, but does not allow zinc to be transferred to the passive state and thus provide its reliable protection in a humid atmosphere.

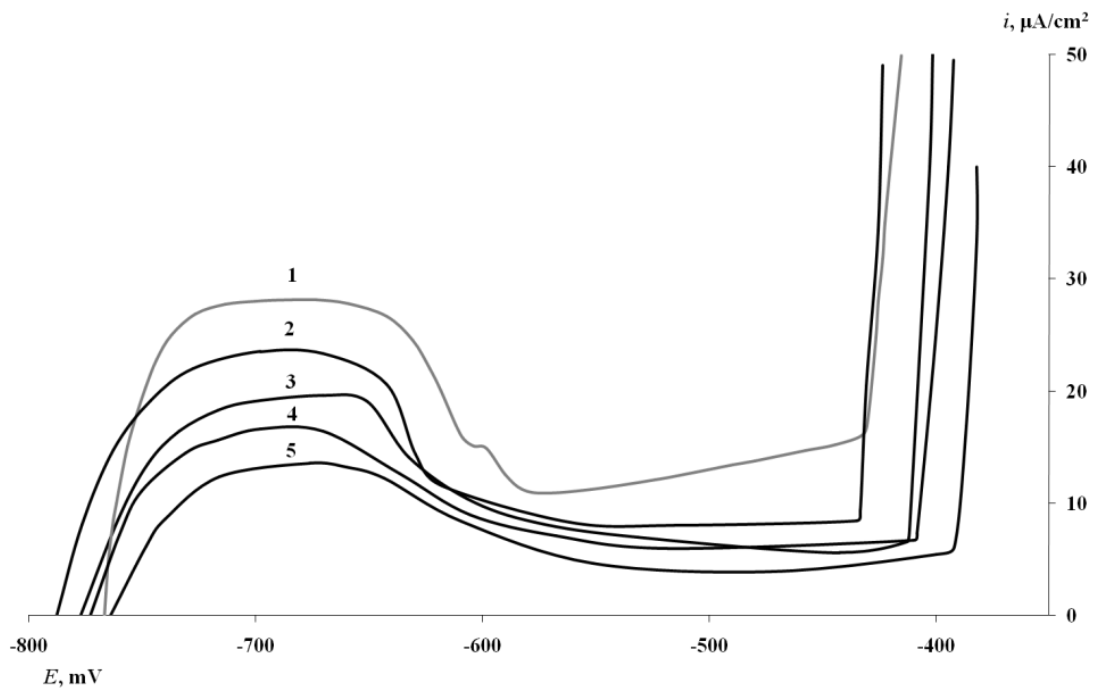

Figure 4. Anodic polarization curves of zinc in borate buffer ( $\mathrm{pH} 7.4)$ containing $1 \mathrm{mM} \mathrm{NaCl}$, without treatment (1) and with pretreatment at $40^{\circ} \mathrm{C}$ for $20 \mathrm{~min}$ in HEDPZn solution with concentration (in $\mathrm{mM}$ ): $2-1 ; 3-5 ; 4-10 ; 5-16$. 
As mentioned above, one of the possible ways to improve the protective properties of phosphonates and decrease their minimum protective concentration is to use it jointly with oxidizers. In [8] it was shown that a formulation of sodium dodecylphosphonate with $m$-SBN inhibits the anodic dissolution of zinc in a borate buffer solution containing $1.0 \mathrm{mM} \mathrm{NaCl}$ ( $\mathrm{pH} \mathrm{7.4)} \mathrm{more} \mathrm{effectively} \mathrm{than} \mathrm{its} \mathrm{individual} \mathrm{components.} \mathrm{Under} \mathrm{the} \mathrm{same}$ conditions, $m$-SBN itself, which slightly decreases the rate of zinc anodic dissolution, significantly displaces $E_{\mathrm{pt}}$ in the positive direction: $\Delta E \geq 0.345 \mathrm{~V}$ at $C_{\mathrm{CI}}=10.0 \mathrm{mM}$.

Addition of $m$-SBN to HEDPZn increases the inhibitive efficiency of the latter (Figure 5). Despite the fact that the corrosion current density of zinc in the active dissolution region changes only a little, a combination of the phosphonate and the oxidizer stabilizes the passive state of zinc and prevents the corrosive action of chloride ions. The shift in $E_{\mathrm{pt}}$ in the presence of the formulation of $0.1 \mathrm{mM}$ HEDPZn with $2.0 \mathrm{mM} \mathrm{m}$-SNB is $\Delta E=0.15 \mathrm{~V}$, whereas HEDPZn itself practically does not affect $E_{\mathrm{pt}}$ at $C_{\mathrm{CI}}=0.1 \mathrm{mM}$. An increase in the oxidizer concentration in the mixture with zinc phosphonate leads to a greater increase in $E_{\mathrm{pt}}$, and $\Delta E$ reaches $0.38 \mathrm{~V}$ (Figure 5, curve 6). Thus, $m$-SNB allows the formation of a phosphonate film that is more resistant to local depassivation by chloride ions.

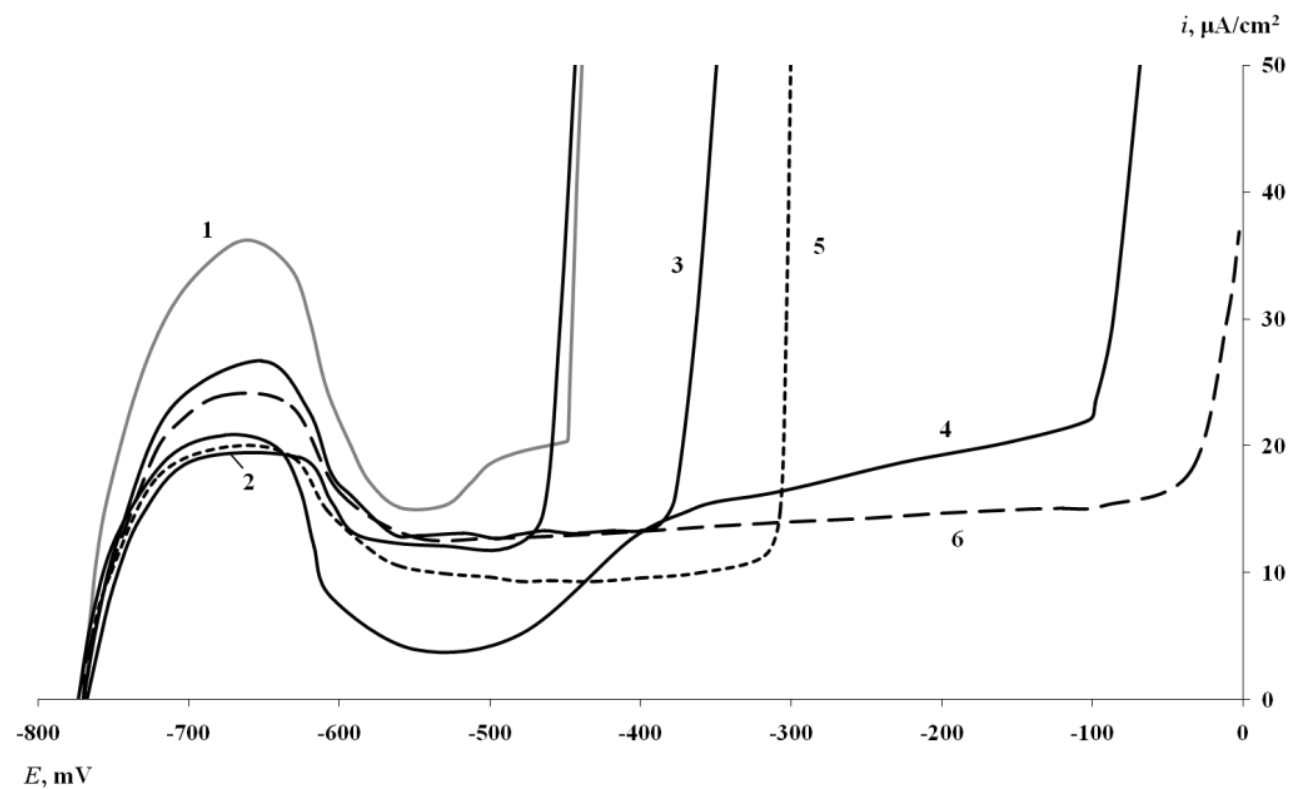

Figure 5. Anodic polarization curves of zinc in borate buffer $(\mathrm{pH} 7.4)$ containing $1 \mathrm{mM}$ $\mathrm{NaCl}$, without (1) and with CI (in mM): $2-0.1$ HEDPZn; $3-2 m$-SNB; $4-10 m$-SNB; $5-0.1$ HEDPZn $+2 m$-SNB; $4-0.1$ HEDPZn $+10 m$-SNB.

Similarly to the mechanism proposed in [7], alkalization of the near-electrode layer in the presence of an oxidizer may lead to further deprotonation of the complex:

$$
[\mathrm{ZnHnL}]^{b-}+\mathrm{OH}^{-}=\left[\mathrm{ZnH}_{(n-1)} \mathrm{L}\right]^{(b+1)-}+\mathrm{H}_{2} \mathrm{O}
$$


As a result, formation of binuclear and/or polynuclear complexes with high stability constants is possible:

$$
\left[\mathrm{ZnH}_{(n-1)} \mathrm{L}\right]^{(b+1)-}+m \mathrm{Zn}^{2+}=\left[\mathrm{Zn}_{(m+1)} \mathrm{L}\right]^{2 m-b-n}+(n-1) \mathrm{H}^{+}
$$

Corrosion tests under conditions of $100 \%$ relative humidity of zinc samples prepassivated in more concentrated solutions of HEDPZn with $m$-SNB showed that the protective effect of their mixture at a constant total $C_{\mathrm{CI}}=32.0 \mathrm{mM}$ significantly depends on the ratio of the components. Apparently, an equimolar formulation of HEDPZn and mSNB is the optimum composition (Figure 6). Treatment of zinc samples in a solution of this mixed CI with $C_{\mathrm{CI}}=32.0 \mathrm{mM}$ allows their corrosion resistance in a humid atmosphere to be increased more than 5-fold compared to the untreated metal. It is important that $\tau_{\text {cor }}$ does not exceed 20-24 h after zinc treatment by components of this formulation $\left(C_{\mathrm{CI}}=\right.$ $32.0 \mathrm{mM}$ ) under the same conditions. This suggests a mutual strengthening of the protective action of the components in the formulation.

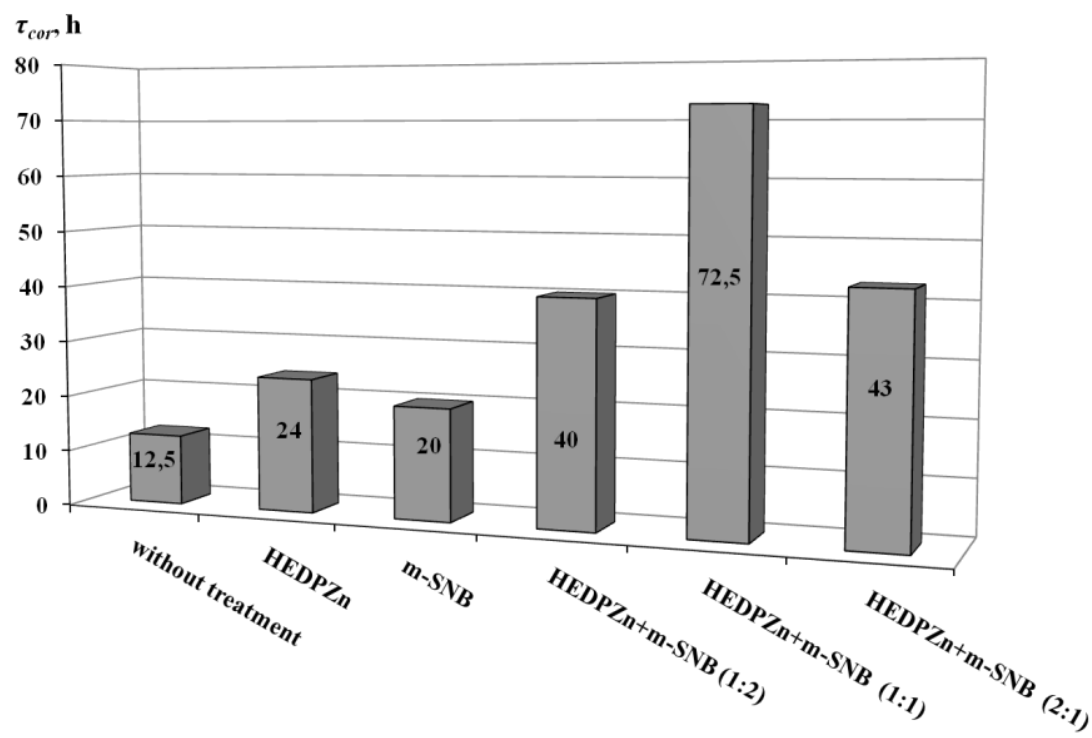

Figure 6. Time of appearance of the first corrosion damage on zinc samples without treatment and with pretreatment at $40^{\circ} \mathrm{C}$ for $60 \mathrm{~min}$ in aqueous solutions of CI $(32.0 \mathrm{mM})$.

Variation of $\tau_{\text {pas }}$ and total $C_{\mathrm{CI}}$ showed that the treatment in a solution of HEDPZn with $m$-SNB (1:1) with $C_{\mathrm{CI}}=32.0 \mathrm{mM}$ at $t_{\mathrm{pas}}=40^{\circ} \mathrm{C}$ and $\tau_{\mathrm{pas}}=60 \mathrm{~min}$, apparently, is the optimal approach that allows one to achieve the best anticorrosive protection of zinc in a humid atmosphere. Decreasing $C_{\mathrm{CI}}$ to $20.0 \mathrm{mM}, t_{\text {pas }}$ to $20^{\circ} \mathrm{C}$, as well changing $\tau_{\text {pas }}(20$ or $120 \mathrm{~min}$ ) accelerates the appearance of the corrosion damage on the samples (Table 2).

In order to enhance the corrosion resistance of zinc in a humid atmosphere, a two-step treatment was tested: preliminary modification of its surface in an HEDPZn solution with $m$-SNB and subsequent passivation in an aqueous solution of SOL. SOL is one of the cheapest, industrially available and effective CI among unsaturated carboxylic acids, which 
has been in use for a long time as the main component in passivating solutions for the inter-operational and temporary protection of metals $[17,18]$. This treatment significantly improved the corrosion resistance of zinc under harsh conditions of $100 \%$ relative humidity. Two-step passivation of zinc in a solution of an equimolar mixture of HEDPZn and $m$-SNB with $C_{\mathrm{CI}}=32.0 \mathrm{mM}$ at $t_{\mathrm{pas}}=40^{\circ} \mathrm{C}$ and $\tau_{\mathrm{pas}}=60 \mathrm{~min}$, and then in a solution of SOL at $t_{\mathrm{pas}}=40^{\circ} \mathrm{C}$ and $\tau_{\mathrm{pas}}=20 \mathrm{~min}$ provided the corrosion protection of samples in the humid atmosphere for $100 \mathrm{~h}$ (Table 3).

Table 2. Results of corrosion tests of zinc samples pre-passivated in aqueous solutions of HEDPZn with $m$-SNB.

\begin{tabular}{ccccc}
\hline No. & $\begin{array}{c}\text { The composition of the passivating } \\
\text { solution }(\mathbf{m M})\end{array}$ & $\boldsymbol{t}_{\text {pas }},{ }^{\circ} \mathbf{C}$ & $\boldsymbol{\tau}_{\text {pas, }}, \mathbf{m i n}$ & $\boldsymbol{\tau}_{\text {cor }}, \mathbf{h}$ \\
\hline 1 & without treatment & - & - & 12.5 \\
\hline 2 & 10 HEDPZn & 40 & 20 & 27.0 \\
\hline 3 & $10 m$-SNB & 40 & 20 & 17.0 \\
\hline & & & 20 & 39.0 \\
4 & 10 HEDPZn $+10 m$-SNB & 40 & 60 & 56.5 \\
& & & 120 & 38.0 \\
\hline & & 40 & 20 & 70.0 \\
5 & 16 HEDPZn $+16 m$-SNB & 60 & 72.5 \\
& & 20 & 120 & 49.0 \\
\hline 6 & 16 HEDPZn $+16 m$-SNB & 60 & 15.0 \\
\hline
\end{tabular}

Table 3. Results of corrosion tests of zinc samples pre-passivated in aqueous solutions of CI.

\begin{tabular}{|c|c|c|c|c|}
\hline № & $\begin{array}{l}\text { The composition of the passivating solution } \\
(\mathrm{mM})\end{array}$ & $\tau_{\text {pas }}, \min$ & $t_{\text {pas, }},{ }^{\circ} \mathbf{C}$ & $\tau_{\mathrm{cor}}, \mathrm{h}$ \\
\hline 1 & Without treatment & - & - & 12.5 \\
\hline 2 & $10 \mathrm{SOL}$ & 20 & \multirow{8}{*}{40} & 26 \\
\hline 3 & $16 \mathrm{SOL}$ & 20 & & 75 \\
\hline \multirow{2}{*}{4} & 1 layer: 10 HEDPZn $+10 m$-SNB & 20 & & \multirow{2}{*}{51} \\
\hline & 2 layer: $10 \mathrm{SOL}$ & 20 & & \\
\hline \multirow{2}{*}{5} & 1 layer: 16 HEDPZn $+16 m$-SNB & 20 & & \multirow{2}{*}{70} \\
\hline & 2 layer: $16 \mathrm{SOL}$ & 20 & & \\
\hline \multirow{2}{*}{6} & 1 layer: 16 HEDPZn $+16 m$-SNB & 60 & & \multirow{2}{*}{100} \\
\hline & 2 layer: $16 \mathrm{SOL}$ & 20 & & \\
\hline
\end{tabular}


Taking into account that after treatment under the same conditions separately by the formulation of HEDPZn with $m-\mathrm{SNB}$ at $C_{\mathrm{CI}}=32.0 \mathrm{mM}$ or by SOL with $C_{\mathrm{CI}}=16.0 \mathrm{mM}$, $\tau_{\text {cor }}$ does not exceed 72.5 and $75 \mathrm{~h}$, respectively, this method of passivation extends the corrosion resistance of zinc in the humid atmosphere by $26 \mathrm{~h}$ on average. At the same time, compared with untreated zinc samples, two-step treatment allows $\tau_{\text {cor }}$ to be increased 8fold. Decreasing the $t_{\mathrm{pas}}$ or $C_{\mathrm{CI}}$ at any stage has an adverse effect on the corrosion protection of zinc under these conditions and significantly reduces $\tau_{\text {corr }}$. Thus, the use of SOL as a post-treatment of a zinc surface modified by a solution of HEDPZn with $m$-SNB allows its resistance to corrosion in a humid atmosphere to be increased.

\section{Conclusion}

1. HEDPZn has an inhibiting effect on the corrosion-electrochemical behavior of zinc both in a chloride-containing borate buffer solution and in a humid atmosphere. The inhibiting ability of the HEDPZn depends on its concentration, exposure time of the metal in the solution with $\mathrm{CI}$, and the solution temperature.

2. Addition of an oxidizer, $m$-SNB, enhances the inhibiting properties of HEDPZn in zinc passivation. Increasing the temperature of the passivating solution, treatment time and inhibitor concentration facilitates the formation of protective layers by the mixture of HEDPZn with $m$-SNB and enhances their resistance in a humid atmosphere.

3. Layer-by-layer passivation of zinc by an inhibitor formulation consisting of HEDPZn and $m$-SNB followed by treatment in a SOL solution allows its corrosion resistance under harsh conditions of $100 \%$ relative humidity to be increased.

\section{References}

1. G.B. Hatc and P.H. Raltson, Aminimethelenephosphonate-zino mixtures control oxygen corrosion, Mater. Perform., 1972, 11, no. 1, 39-42.

2. N.M. Dyatlova, V.Ya. Temkina and K.I. Popov, Complexones and Metal Complexonates, Khimiya, Moscow, 1988, 544 (in Russian).

3. Yu.I. Kuznetsov, Organic corrosion inhibitors: where are we now? A review. Part IV. Passivation and the role of mono- and diphosphonates, Int. J. Corros. Scale Inhib., 2017, 6, no. 4, 384-427. doi: 10.17675/2305-6894-2017-6-4-3

4. K. Aramaki, The inhibition effects of chromate-free, anion inhibitors on corrosion of zinc in aerated $0.5 \mathrm{M} \mathrm{NaCl}$, Corros. Sci., 2001, 43, 591-604. doi: 10.1016/S0010938X(00)00085-8

5. Yu.I. Kuznetsov and E.A. Trunov, On the mechanism of the inhibiting action of zinc phosphonates in neutral media, Zh. Prikl. Khim., 1984, 57, no. 3, 498-504 (in Russian).

6. Yu.I. Kuznetsov, Physicochemical aspects of metal corrosion inhibition in aqueous solutions, Russ. Chem. Rev., 2004, 73, no. 1, 75-87. doi: 10.1070/RC2004v073n01ABEH000864 
7. Y.I. Kuznetsov and V.A. Isaev, On the influence of an oxidizer on the inhibiting effect of hydroxyethylidene diphosphonic acid, Prot. Met., 1991, 27, 753-759.

8. G.V. Zinchenko and Y.I. Kuznetsov, Effect of oxidants on protection of mild steel by zinc hydroxyethylidenediphosphonate, Prot. Met., 2005, 41, no. 2, 167-172. doi: 10.1007/s11124-005-0023-2

9. G.V. Redkina, A.S. Sergienko and Yu.I. Kuznetsov, Effect of sodium dodecylphosphonate and its formulations and sodium m-nitrobenzoate on the anodic behavior of zinc in a chloride-containing borate buffer, Korroz.: Mater., Zashch. (Corrosion: Materials, Protection), 2019, 9, in Russian (in press).

10. I.L. Rozenfel'd, Metal corrosion inhibitors, Moscow, Chemistry, 1977, 352 pp. (in Russian).

11. E.E. Foad El Sherbini and S.S. Abd El Rehim, Pitting corrosion of zinc in $\mathrm{Na}_{2} \mathrm{SO}_{4}$ solutions and the effect of some inorganic inhibitors, Corros. Sci., 2000, 42, 785-798. doi: 10.1016/S0010-938X(99)00081-5

12. Yu.I. Kuznetsov, A.A. Chirkunov and I.A. Filippov, On the influence of surface modification of steel by oksietilidendifosfonovaya of zinc on treated it with a solution of some inhibitors, Electrochemistry, 2013, 49, no. 12, 1235-1242.

13. A.A. Chirkunov, I.A. Filippov and Yu.I. Kuznetsov, Effect of copper hydroxyethylidene diphosphonate on the passivation of low carbon steel with organic inhibitors, Korroz.: Mater., Zashch. (Corrosion: Materials, Protection), 2013, 7, 29-34 (in Russian).

14. G.V. Lisichkin, A.Y. Fadeev, A.A. Serdan, P.N. Nesterenko, P.G. Mingalyov and D.B. Furman, Chemistry of Surface Grafted Compounds, Ed.: G.V. Lisichkin, Moscow, Fizmatlit, 2003, 111 pp (in Russian).

15. M.V. Rylkina and Yu.I. Kuznetsov, Influence of the nature of anions on the initial stages of zinc depassivation in neutral media, Korroz.: Mater., Zashch. (Corrosion: Materials, Protection), 2008, 2, 1-7 (in Russian).

16. Yu.I. Kuznetsov, Organic inhibitors of corrosion of metals, N.Y., Plenum Press, 1996, $283 \mathrm{pp}$.

17. Yu.I. Kuznetsov, Progress in corrosion inhibition of metals and modification of protective nanolayers on metals, Korroz.: Mater., Zashch. (Corrosion: Materials, Protection), 2011, 1, 1-10 (in Russian).

18. A.A. Chirkunov, Yu.I. Kuznetsov and A.S. Gorbachev, On modification of passivating formulations IFHAN-39 for steel protection from atmospheric corrosion, Korroz.: Mater., Zashch. (Corrosion: Materials, Protection), 2010, 5, 30-34 (in Russian). 